\title{
How to Fundraise for Stigmatized Groups
}

\author{
EUN A JO | CORNELL UNIVERSITY
}

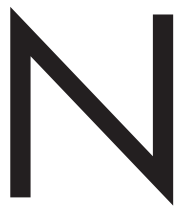

GOs face a dilemma: when they seek to raise funds for groups that are most in need, the stigma associated with them often reduces donations. This concern has led some NGOs to exclude the stigmatized groups: HIV prevention programs have omitted those at risk through sexual activity in Europe and poverty relief programs have denied help to the "ultra-poor" in Southeast Asia. In an attempt to reduce stigma, other NGOs have sought to highlight the shared linkages between donors and recipients-based on race, ethnicity, or religion-or made universalistic appeals to human rights. But which is the best strategy?

In their study for the American Political Science Review, Katerina Linos, Laura Jakli, and Melissa Carson recommend a fundraising strategy that is broad-based and need-oriented. That is, rather than narrowly target them, NGOs should widen the scope of their programs to include more stigmatized groups; and instead of emphasizing their rights, NGOs should underscore the needs of the beneficiaries.

These insights are based on an innovative experiment in Greece involving a nation-wide text-to-give campaign. Such campaigns are common in Greece; major phone carriers allow registered NGOs to fundraise through texts up to three times

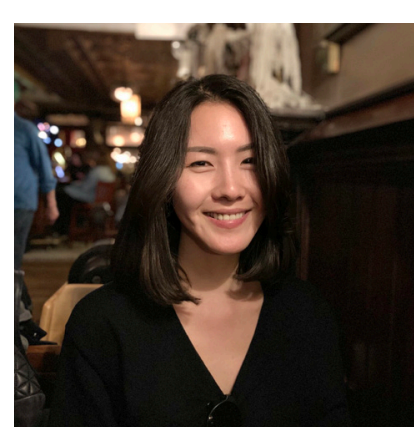
a year. By partnering with a Greek NGO and soliciting donations, the authors were thus able to unobtrusively study the generosity gaps in Greece as well as strategies to reduce them.

In the experiment, the NGO sought to fundraise for the Diatrofi Program, which provides free lunch to the poorest public

Eun A Jo is a PhD student in the Government Department at Cornell University specializing in international relations and comparative politics. She is interested in political narratives, emotions, and the domestic politics of international relations, with a focus on East Asia.

In the APSA Public Scholarship Program, graduate students in political science produce summaries of new research in the American Political Science Review. This piece, written by Eun A Jo, covers the article "Fundraising for Stigmatized Groups: A Text Message Donation Experiment" by Katerina Linos, Laura Jakli, and Melissa Carlson. The full article is available at: https://doi. org/10.1017/S0003055420000787

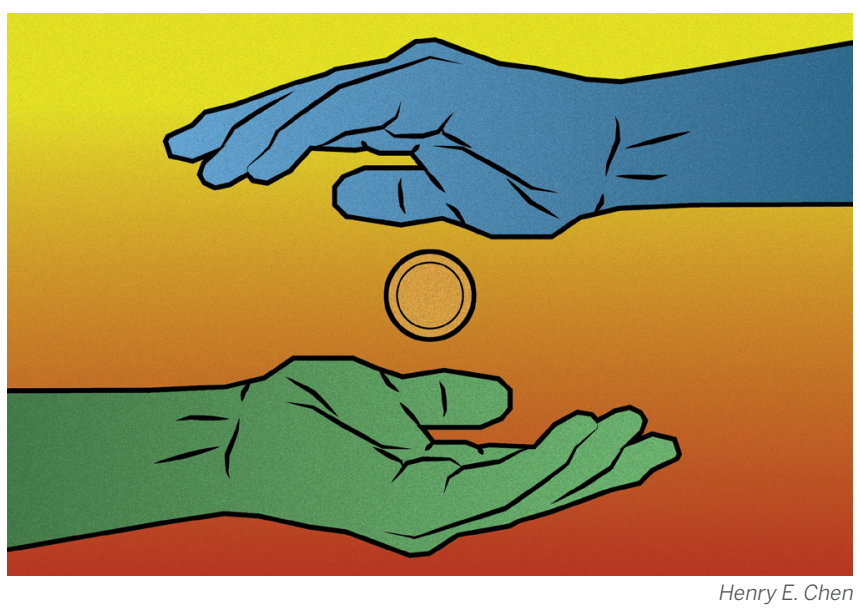

schools in Greece. The texts in this campaign differed in two critical aspects: first, the text specified whether the child was a "Roma," a "Greek," or did not specify any ethnic attributes; second, the text included or excluded a human rights appeal: "every child has a right to food." To complement the experiment, the authors also conducted in-depth interviews with principals from 12 schools that benefited from the program to qualitatively assess the stigma associated with the Roma.

Three findings were notable. First, donations were halved when the recipient was presented as a "Roma" child, but they were similar for either a Greek child or a child of unspecified ethnicity. This suggested that generosity gaps were driven by stigma against the Roma rather than a preference for the majority ethnicity. Second, despite being a standard practice among NGOs, an appeal for universal rights did not reduce the generosity gap. Finally, when donors were located close to Roma communities, their generosity fell in general, but disproportionately so for a Roma child. The interviews confirmed the widespread prejudice against the Roma and their limited interaction with the ethnic Greeks; while in-kind donations to the segregated Roma schools were not uncommon, they were based on perceived need, rather than the rights, of the Roma.

Together, the findings suggest that NGOs should reconsider their fundraising strategies when seeking to help stigmatized groups. Specifically, they challenge the wisdom of common advocacy frames, such as appeals to shared ties and human rights. The best strategy may, in fact, be the simplest one: focusing on the needs of the recipients and not specifying the group to which they belong. This would allow NGOs to raise more and reach farther. 